\title{
Teachers' action research in a culture of performativity
}

Article

Accepted Version

Cain, T. and Harris, R. (2013) Teachers' action research in a culture of performativity. Educational Action Research, 21 (3). pp. 343-358. ISSN 1747-5074 doi:

https://doi.org/10.1080/09650792.2013.815039 Available at https://centaur.reading.ac.uk/37660/

It is advisable to refer to the publisher's version if you intend to cite from the work. See Guidance on citing.

Published version at: http://dx.doi.org/10.1080/09650792.2013.815039

To link to this article DOI: http://dx.doi.org/10.1080/09650792.2013.815039

Publisher: Taylor \& Francis

All outputs in CentAUR are protected by Intellectual Property Rights law, including copyright law. Copyright and IPR is retained by the creators or other copyright holders. Terms and conditions for use of this material are defined in the End User Agreement.

\section{www.reading.ac.uk/centaur}

\section{CentAUR}

Central Archive at the University of Reading

Reading's research outputs online 
Teachers' action research in a culture of performativity

$\operatorname{Tim}_{\text {Cain }}{ }^{\mathrm{a}}$ and Richard Harris ${ }^{\mathrm{b}}$

${ }^{a}$ Faculty of Education, Edge Hill University, Ormskirk, UK; ' Institute of Education,

University of Reading, Reading, UK

In a culture of performativity, action research offers teachers an opportunity to step back and reflect on their practice. This paper reports on a collaborative project carried out between a university and a secondary school in England, in which the university staff supported an action research project within the school. Five school teachers volunteered to engage in this project. They were given an introduction to action research and were assigned a university researcher to support them. Despite the common input and a common school culture, the teachers engaged in very different models of action research. This article reports on two teachers whose approaches were dissimilar. It examines these differences and suggests that they can be explained by considering the teachers' different responses to a performativity culture.

Keywords: teacher research; performativity; emancipatory; technical; action research

The challenge of change and the promise of action research In recent years, education in many countries has been subject to continual change and there are concomitant pressures on school teachers constantly to improve their educational practices (Priestley 2002; Barker 2008). In a powerful article, Ball $(2003,215)$ describes these policy pressures as an epidemic, 'An unstable, uneven but apparently unstoppable flood of closely inter-related reform ideas'. He argues that forces of marketisation, managerialism and performativity act so as to shift educational endeavour entirely to focus on what can be measured, through 'the translation of complex social processes and events into simple figures or categories of judgement' $(2003,217)$. Thus the technologies of performativity, 'the data-base, the appraisal meeting, the annual review, report writing, the regular publication of results' (Ball 2003, 220), pressurise teachers and other education professionals to subject themselves to constant appraisal and measurement, setting and meeting (or exceeding) targets so as to demonstrate they are "better than others ... "outstanding", "successful", "above the average"' $(2003,219)$. Ball $(2003,217)$ points out that the demands of performativity are presented as 'misleadingly objective and hyper-rational' but he quotes teachers articulating a sense that these demands seriously distort their view of themselves as teachers - their beliefs, ideals, commitment and even identity:

Increasingly, we choose and judge our actions and they are judged by others on the basis of their contribution to organizational performance, rendered in terms of measurable outputs. Beliefs are no longer important - it is output that counts. Beliefs are part of an older, increasingly displaced discourse. (Ball 2003, 223)

Thus, in a culture of performativity: 
A new kind of teacher and new kinds of knowledges are 'called up' by educational reform - a teacher who can maximize performance, who can set aside irrelevant principles, or out-moded social commitments, for whom excellence and improvement are the driving force of their practice. (Ball 2003, 223)

In this context, action research offers a way for teachers to step back and reflect on their actions, in the light of their values. Action research is participatory, democratic and focuses on improving practitioners' ability to make wise judgements in practice (Elliott 1991). It promises both selfimprovement and self-awareness (Judah and Richardson 2006). It is inevitably political because, according to Carr and Kemmis:

The self-critical community of action researchers undertakes to practice values of rationality in communication, justice and democratic participation in decision-making, and fulfilment in work, both in relation to the educational process itself and in relation to the self-educational process of action research. It thus creates conditions under which its own practice will come into conflict with irrational, unjust and unfulfilling educational and social practices in the institutional context in which the action research is carried out. $(1986,197)$

There is evidence that teachers' action research stimulates change in their thinking and practice. Furlong and Salisbury (2005) found that action research often led to teachers becoming more confident and knowledgeable, collecting and using evidence, and learning about their own learning. For some teachers, the nature of their reflection was 'transformed' because the research process led to 'informed reflection' $(2005,61)$. In the USA, Zeichner (2003) found that engaging in action research:

... helps teachers to become more confident in their ability to promote student learning, to become more proactive in dealing with difficult situations that arise in their teaching, and to acquire habits and skills of inquiry that are used beyond the research experience to analyze their teaching. [It] seems to develop or rekindle an excitement or enthusiasm about teaching ... [It can lead to] improvements in students' attitudes, behavior, and learning. The experience of conducting action research [...] seems to help teachers move in a direction of more learner-centered instruction. (Zeichner 2003, 318)

However, Haggarty and Postlethwaite (2003) found that, although teachers usually value action research as a means of professional development, it does not necessarily lead to changes in their practice. They reported that 'Teachers' attitudes to risk were a significant factor in their uptake of new ideas', with risk-averse teachers being unlikely to adopt new ideas, even when they had been found successful by others $(2003,438-440)$. They also found that the research under study was, 'not seen as threatening to the systems and structures of the school, but as supportive in generating improvements within that broadly agreed framework' $(2003,431)$. In this sense, it was not emancipatory for the teachers.

The emancipatory aspect is central to many understandings of action research. Grundy (1982), drawing on Habermas, distinguished between technical, practical and emancipatory action research - a distinction that was further developed in Carr and Kemmis (1986). According to the latter text, technical action research involves externally formulated questions and issues that are not based in practical concerns of teachers and might therefore be inauthentic for practitioners, who are co- 
opted into the research process. Technical action research aims for greater efficiency or effectiveness and takes an instrumental view as to what these might mean, although it '... can produce valuable changes in practice ... may encourage practitioner to begin more intensive analyses of their own practices ... [and] may assist teachers to develop skills in self-monitoring' $(1986,202-$ 203). Practical action research goes beyond technical matters; it involves cooperative relationships between practitioners and external facilitators; it aims to develop professional wisdom (understanding as embedded in praxis); and its criteria for improvement may change because these are seen as 'problematic and open to development through self-reflection'; that is, not imposed, from outside. Emancipatory action research aims to emancipate participants from 'tradition, precedent, habit, coercion or self-deception':

In emancipatory action research, the practitioner group itself takes responsibility for its own emancipation from the dictates of irrationality, injustice, alienation and unfulfillment. It explores such things as habits, customs, precedents, traditions, control structures and bureaucratic routines in order to identify those aspects of education and schooling which are contradictory and irrational. (Carr and Kemmis 1986, 204)

With responsibility for the research being taken by the participants, any outside assistant assumes the role of a collaborative 'moderator'. Emancipatory action research incorporates a social justice perspective, provoking a critical response to organisational constraints, and aims to transform organisations and even education itself, rather than simply the practices of individuals, through developing 'common practical theories, authentic insights and prudent decision making (based on mutual understanding and consensus)' (Kemmis 2007, 177).

Although Carr and Kemmis (1986) declare that emancipatory action research '... best embodies the values of a critical educational science' (203), it is not easily realised in schools. Kemmis $(2006,462)$ argues that action research has the potential to change 'schooling' (by which he meant the institutional processes that prepare individuals to participate in cultural, social and economic life) to make it more 'educational' (developing the knowledge, values and capacities of individuals and society more generally, towards the development of self-expression, self-development and selfdetermination). Kemmis laments:

Much of the action research that has proliferated in many parts of the world over the past two decades has not been the vehicle for educational critique we hoped it would be. Instead, some may even have become a vehicle for domesticating students and teachers to conventional forms of schooling. $(2006,459)$

Anderson, Herr, and Nihlen (1994) explain that many teachers (not only head teachers) have an interest in supporting their schools' bureaucratic routines, norms, rules, skills and values because these provide a means of control: when understood and employed, they can provide a sense of competence. Thus, 'Practitioner research either can reproduce those norms, rules, skills and values or it can challenge them' (Anderson et al. 1994, 25). They cite Hutchinson and Whitehouse (1986) who, reviewing teacher research projects, found that there was an inevitable tension between the collegial and democratic nature of action research and the hierarchical nature of school management. Anderson et al. (1994, 23-26) argue that this tension can lead to teachers researching relatively trivial matters in a way that does not threaten the school's status quo. Gewirtz et al. (2009, 570), discussing alternative conceptions of teacher research, identified ambiguity around 'whether 
teacher research reflects a concern to help teachers to meet national targets more effectively' or whether it empowers teachers, 'cultivating them as creators of their own knowledge, better able to control their working lives'. They associate the first conception with 'problem-solving' approaches to action research, whilst the second conception involves 'problem-making' approaches, in which teachers start by 'problematising their own and others' taken-for-granted assumptions' (2009, 570571). Furthermore, Ponte et al. (2004) found that, when undertaking action research with little direction, teachers tended to develop their knowledge about educational methods, techniques and strategies; only when they were actively encouraged to broaden their reflection did they develop other types of knowledge, including knowledge about educational norms, values and objectives.

The study

This study was conceived in a conversation between the head teacher of 'Trinity Boys' School' and one of this paper's authors. The head teacher said that he wanted to improve teaching and learning in the school; the researcher responded that action research might help, and offered to support the teachers in what they wanted to achieve, if he and his colleagues were able to research the process. Originally we wanted to know how the teachers perceived action research, how they planned it and carried it out, and how they sustained their motivation. As the research unfolded, it became clear they were engaging with action research in different ways and we became interested in trying to explain this. Given that the teachers were working in the same school, we also wanted to explore the factors in the institutional context that shaped their differing views of action research.

Following further conversations, a one-year project was developed. Five teachers volunteered and came to the university for a day in July 2010 , to learn about action research and the principles underlying this approach to investigating practice. As a group the teachers identified a common concern around pupil independence; they felt that their students relied heavily on being 'spoon-fed' information, rather than being active seekers of knowledge, and so this was the area they chose to investigate. This was an important step, as action research starts with the concerns of the practitioner. The intention was that they would develop a collaborative project around this topic, but because school timetable constraints made collaborative meetings difficult, the teachers planned and implemented individual projects. Each project centred loosely on the theme of pupil independence but they diverged, as the teachers identified specific issues of interest to them and planned their actions accordingly, in collaboration with us. Each teacher was assigned a university lecturer.

Our role was to provide individual support for the teachers' projects, acting as sounding boards for ideas and as critical friends; we did not 'tell' the teachers what to do, but challenged their thinking, helping them clarify what they wanted to work on and how they might investigate it in an appropriately rigorous manner within the confines of the project. We visited the teachers at the school individually once a month through September-December and again in July 2011; we also maintained contact by email and telephone, through the year. These communications, besides offering support for the projects, allowed us to research the ways in which the teachers' projects developed; they also gave us some understanding of the school as a whole. Data included semistructured interviews which were conducted on each visit and were audio-recorded and transcribed; the transcripts were coded inductively. Data also included written materials, including worksheets and emails. 
'Trinity' is a small, boys' comprehensive (age 11-16) school in England. Situated in a medium-sized town, it admits boys from a wide geographical area. Its public examination results are slightly above the national average and its most recent inspection report finds the school 'satisfactory' with several 'good' features. In addition to their normal duties, all teachers participate in a 'School Improvement Group' (SIG) that aims to share good practice; the project teachers were expected to present their work to colleagues via these groups. The SIGs run during the autumn term only, as thereafter the school wants the staff to concentrate on preparing pupils for the examinations in the summer term. The SIGs have the potential to add a further level of collaboration but, as will be seen below, this was a 'doubleedged sword' at times. In this report, names have been altered for reasons of confidentiality.

Case 1: 'Amy'

Amy's starting point in this project was a desire to improve the number of $A / A^{*}$ grades the English department obtained. She admitted there had been a focus on the C/D borderline and she had a reputation as someone who could get good results from borderline pupils. 1 However, the school was concerned about the lack of $A / A^{*}$ grades and Amy wanted to address this area but was also concerned that a focus on this would not benefit pupils at a lower grade:

I've been very typecast as a C, D borderline teacher for a long time, if I'm honest, as someone who can get kids Cs ... and actually I'm bored of that ... and I want to sort of challenge and do something different ... I always end up with the set twos and threes, I never get the set ones. This year I've got a set one and I want to just be a different type of teacher with set one.

This shows a sense of frustration about how she is perceived, and a desire to improve. As a teacher she had had a varied career, teaching in four schools, including a year in Australia:

I've been a head of department for a long time and I was getting very disillusioned with being a head of department because of paperwork ... so last year I decided to go for my AST [Advanced Skills Teacher - a promoted role for teachers who can demonstrate good teaching practice to colleagues] instead because really what I like doing is teaching, not anything else ... and the head was really keen that we had an AST in English and so I did that last year and so I really wanted this year to do something where I was developing teaching and learning ... This project was coming up and I thought, you know, that's perfect because ... I'm going to get an opportunity to try and develop something that's new.

She had had few opportunities to develop personally - as an AST she was expected to provide support and develop others but received little in return. This project therefore offered a welcome opportunity for personal development. In many ways, Amy was fitting into the demands of the school. Her research focus was on examination results, her intervention was to focus more on the $A / A^{*}$ examination criteria in lessons as she felt this would help pupils better understand what was expected and therefore allow them to get better results; she was also leading a SIG that had a focus on how the school supported the more able students.

There had been a change in the school ethos towards professional development (hence the SIGs) but this seemed tied to a results-driven agenda. Amy evidently cared for her pupils and their success, 
often saying they deserved better and she needed to do something to bring about a change. She talked about being a risk-taker:

it's taking the risk, isn't it, but, you know, you don't get any results unless you take a risk, do you? ... ok, we could do little things but actually, you're right, unless I really push it in a way is there any point to doing the research?

This aspect emerged more strongly during the interview as we discussed what she could do. Her initial ideas were focused on examination results, but further discussion revealed that she wanted pupils to be more independent in their work and gain a greater understanding and love of English. She also wanted to get more personal satisfaction from her own teaching:

I want to have that, you know that buzz when you're teaching and you just think, cor, that was great today and when you actually can't wait to come in the next day because you're going to be trying that with the class ... I want to go back to having that sort of chance to play a bit.

She was already trying to discover new ideas for her lessons and had recorded a series of television programmes with Dylan Wiliam. Following suggestions from the university researcher working with her to read the work of Neil Mercer on exploratory talk, the discussion moved towards a different focus:

I could think about what it is that they need to be able to do in English to make them successful and then actually teach to that rather than teach to the exam.

Before the second interview, Amy had read the work of Neil Mercer and was implementing some pedagogical practices to promote better quality talk in the classroom as a means of developing higher quality thinking. She remarked that she had been training students to pass an examination rather than teaching them and that this had blunted her own creativity. She was also aware that she would have to change her teaching approach if the new ideas were to be successful. As she said,

'it's hard, isn't it, to let go' and she knew she had to step back from dominating the class and directing it. She also realised that there would be no instant changes and was prepared to work at the changes across the remainder of the year.

To an extent Amy seemed to be seeking reassurance during this interview. There were a lot of instances of rhetorical 'isn't it' in her discussion and she was worried the project was heading in the 'wrong' direction, saying 'am I on the right track now or am I sort of going off at a tangent?' Towards the end of the interview after we had discussed her ideas, she said:

feel more comfortable now ... I was feeling I'm going off at a tangent and this is becoming a project about talk but now I'm glad it isn't ...

She was excited by implementing new ideas and she felt the lessons were getting progressively better as the students became more used to the new style of lessons. Amy was starting to re-enjoy her teaching much more and was already experimenting with using the same ideas with another year group to see how well they would work. She also felt that pupils were enjoying the lessons more: 
I do think there is a sense of excitement when they come in the room ... they're pleased to enter the classroom and they're not ... preparing to leave before the bell's gone ... One of the talk lessons we had this week, it was lunch, three of them stayed behind to carry on the conversation and it's only a small thing but that sort of makes you think, well, you know, they've enjoyed it. I know that one or two of them, it's really helping, I know, I can just see it on their faces that their light's switched on ... particularly some of the kids who can get quite easily disaffected ... I can see that they're more into it than they used to be ...

She was also starting to talk as if the enjoyment of the lessons mattered more than the final results:

I'm doing it particularly with poetry ... they are not very good at having an opinion about a poem, they're good at me saying, 'the simile's there because of this' ... I think it'll really make a difference but if it doesn't they've enjoyed it ... they're entitled to enjoying it, actually.

Overall, Amy felt that the project was liberating her:

I'm feeling much more confident with this and that I'm the sort of teacher I want to be not the sort of teacher that's bound by the rules. I feel like I'm taking a risk but I feel good for doing it.

She had found the reading very interesting; this suggested diligence in tracking it down and using it. The role of the SIG acted as a further impetus to her study as the group had become more focused on promoting independent work, which fitted with what Amy was doing.

By the third interview Amy felt that pupils were still enjoying the new teaching approach more, although she admitted the head teacher would probably not be pleased that her focus was no longer purely on results. The SIG had also started to try out new ideas but Amy was concerned that teachers had different expectations of what they regarded as a good lesson. One of the teachers in Amy's SIG had adopted some of her ideas but was observed by another teacher who was critical of what she saw and the feedback on her teaching had been unduly critical; Amy felt this was because the observer taught in a more didactic style and was uncomfortable with the ideas being trialled. This is one of the examples where the potential collaborative nature of the SIGs failed to be realised due to the beliefs held by individuals, which were seen to be in conflict with the ideas being presented. Amy's own lessons were still going well with heightened levels of pupils' engagement:

Definitely, definitely enjoying it more ... they sort of like run in the door, some of them ... so definitely, I would say, the sense of enthusiasm and enjoyment's better and their engagement because of that.

I think they've become much more confident in their learning ... the revision classes were packed, I mean, like falling out the door packed, full of kids who wanted to come and some kids I didn't teach but who'd heard [about them].

The pupils had done mock examinations prior to the interview; Amy had marked one set of papers, and although there was no dramatic improvement in results, they had not suffered as a result of the new ideas being tried. There were two cases where Amy could identify a big improvement in pupils' work and overall she was pleased with what had happened so far because both the pupils and Amy were enjoying the lessons more: 
once you're immersed in it, you're kind of enjoying so much what you're doing that the grades ... can be a blocker maybe to doing something really creative and I think at the beginning I was very conscious of it and ... I just don't think I am now.

There had been a distinct change in Amy's lesson approach (where the presence of an observer reinforced the value of the ideas being implemented):

I had an observer in for the lesson and that was a lesson I taught where I did very little. I would say probably ninety-five percent them and five percent me was the idea ... and I was quite nervous about it because I wasn't quite sure how it was going to go, but it was really good and it was quite interesting how much they talk on task actually when you allow them to.

She was also aware that the project focus had shifted:

I feel like it's been a bit of a journey that started with As and A stars and it's not really about that now ... it's kind of more about producing lessons which are much more pupil centred, like there's less of me and more of them, where it's more them stretching the creative side of their brain, opportunities for talk that I wouldn't always do, a lot more group work than I've ever done, particularly with groups that I might find a bit challenging and shy away from.

At the start ... I was more concerned about what grade they came up with and now I think I'm more concerned that they leave here with an enriching and creative and happy time.

The project appeared to have a big impact on Amy, prompting her to reappraise her practice, explore fundamental questions about what she wants to achieve in her teaching and why and how pupils should be educated:

I've really enjoyed and I do think it's changed me, I think it's changed the way I teach. I'm hoping it's changing other people in the school too. It's changed, you know, the kids' impression of English, I think, and improved their enjoyment of it.

The motivation for the project started as an external stimulus to improve results but created an energy of its own, becoming self-motivating and self-fulfilling.

Amy was interviewed again towards the end of the academic year to see how the project had progressed. Although she still felt it had refreshed her teaching and given her a clear view of what she wanted to achieve, several things had diverted her focus. In January the whole school had become more focused on results in preparation for the examinations that would start in May - Amy said the school had become 'exam city'. The SIGs had finished (although they would restart in the following September), which had removed one incentive for carrying out her ideas.

More importantly, the school had replaced her top-set teaching group with a C/D borderline group. Amy had tried using her new teaching approaches with this group but recognised that embedding the approaches takes time and, in the build up to the examinations, this proved too difficult. Amy felt frustrated by the situation as she felt she had lost some momentum. She was also anxious about the examination results - if they were better than usual she would feel authorised to continue with her ideas and to spread them further throughout the school; if they were no worse she would also feel able to continue with her ideas, based on how pupils responded to the new style lessons and 
how she felt about her teaching. However, if the results were worse, she would have no grounds for continuing with her ideas.

Amy had received some encouragement. She had continued to implement the ideas with a group of 13-14 year olds she been teaching all year and was pleased with the results, feeling they were better prepared to tackle GCSE English. A physical education teacher had heard about her approaches and wished to incorporate them into his physical education theory lessons. The feedback Amy received from this teacher was very positive, and pupils noticed similarities between what the two teachers were doing. However, the biggest motivators for Amy were the pupils' responses: she had changed their expectations of English lessons, and increased her own sense of enjoyment from teaching.

Amy had ideas she wished to follow up in the next academic year; she wanted to work with a SIG to develop more independent learning, to re-work the relevant schemes of work to reflect new teaching approaches and to spread the practice across the English department. Once the formal interview was finished she then proceeded to talk with great enthusiasm about the lesson she had planned for her class of 13-14 year olds later that day, so although her plans had been diverted by the school's decisions she had retained a clear sense of what she wanted to do, but there were concerns as to how much agency she felt she had over the process.

Case 2: 'James'

James had come into teaching after a career, first in the merchant navy, then doing project management in the Far East, then in technical sales and finally in management. He switched to teaching at 'a difficult time' in order to have more time for his children. Having an engineering degree, he did a Postgraduate Certificate in Education in mathematics and then a Master of Science (MSc) and was currently in his fifth year of teaching. At first, James identified his concern as 'the lack of understanding amongst students of where they are and where they should be' and he wanted 'to improve their understanding of where they need to develop in maths, to achieve their potential'. He thought the situation could be improved by awarding National Curriculum levels to classwork and homework and he thought students might be involved with 'before and after questions - do you understand levels and progress?' Asked 'what interests or excites you about the situation?', he responded:

'Implementing the findings of my MSc, to verify their validity and applicability in the classroom'. He had achieved a distinction on the MSc, in which: I did a comparative study of two schools ... I looked at the modelling that the Fischer Family Trust4 did ... I looked at the targets the school were set themselves and then looked at the actual progress of the students in both schools ... I wanted to look at how I could break that down to smaller chunks that the students could [understand] so I'm looking at actually developing that MSc now into something that I can use in the classroom.

At his first interview, James explained his intervention; when the new students arrived at the school, he would give each student a graph that would plot their mathematical progress through their five years of school:

I would say, right, what do you want to achieve by the end of year eleven, so if they said they were a $2 \mathrm{~A}$ and they wanted to get $\mathrm{a} C$ at the end of Year eleven, I would just literally draw a line. 
Each student's graph would show a straight-line progression between their National Curriculum level on entry and the GCSE grade they hoped to achieve, on leaving.

He explained his reasons:

We have a minimum challenge target for each year but it's just letters to them ... I don't think they really associate that with their progress, so I'm interested in trying to associate it with their progress ... to encourage them to actually understand where they are and where they need to be, long term.

He defined 'where they need to be' in terms of GCSE grades because, 'our aim in school is to get them a GCSE, the best grade they could possibly get ... the students are aware of that being their primary objective when they get here'. Every term, the students sit a mathematical test (a 'levelled assessment') and James's plan was to enter their test results on the graphs so they could see whether their progress was better or worse than expected (i.e. above or below the line) and so James could identify 'students that are falling off the map'. James described technical problems, to do with converting national curriculum levels into GCSE grades, which he had addressed by translating both into point scores. His intervention was further complicated by the fact that the present 11-year-old students would take their GCSE aged 14-15, so those who failed to achieve a good grade would have another year to revise and re-sit the examination (as the traditional age to take the GCSE examinations is 15-16). In addition to the graph:

over the term I will say to them, right, we're going to do a review of how you think you're getting on in class ... what do you think your behaviour's like, what do you think your classwork's like, how do you think your homework's going ... and then I can review that as well ... so we are starting to micro manage students more than we would before.

He hoped that this would help improve the student's self-motivation:

What we're trying to do is get them to take responsibility for their progress because, at the end of the day, if they don't take that responsibility for their progress, we won't improve. You can push them to a certain level ... but when you get beyond that level, there has to be a certain amount of involvement from the students. They have to turn round and say, right, I want to do this.

Motivation being critical, he had decided to trial the intervention only with the top set, saying: 'I'm not sure this would work with bottom set because l'm not sure that it would be that motivating'.

By the second interview, James had asked his 11-year-old to 12-year-old students what they wanted to achieve: 'most of them have said they want an A star in year ten (aged 14-15) which is lovely'. He had received notice of their primary school test results and each student now had an individual graph, linking this with their hoped-for grade. He had asked the students to read off, from the graphs, the grade they would expect to achieve each term during their first year in secondary school (aged 11-12) and to enter these in their mathematics books. He said: 'I don't see a lot of risk in doing this because the targets are going to be so close to what we would expect as a school anyway'. He reported feeling 'sort of quite positive' about the project and considered extending it to lower ability students:

Even with the lower ability students, if you think ... they've got fifteen steps [i.e. terms] to get to a GCSE ... and if they do a little bit at a time, they should get a $C$... And just getting that in their heads 
that if they make a little bit of progress every term, you know, even the lower ability ones ... that end goal is achievable.

James had given a brief talk about his intervention to the SIG and reported: 'The head is really interested in this ... he said he's really impressed in what we're looking to do'. Asked about his own learning, he said:

The reading's done, you know, the research is done ... I don't see that I will be doing a lot more research in the way of reading journals and that. I think the research I'll be doing now is into the effectiveness of the model.

By the third interview, James had administered the termly test and 'set a spreadsheet up which automatically calculates what their level is from their score'. The main purpose of his intervention was monitoring progress:

I want to know after this test if I've got people that are not moving, so ... we pick up [those] and pull them to one side and say, look, you've just done the test, you were this at the beginning of the year, you're now this level, you've actually dropped back a bit from where you were. What's going on? What help do you need? What do you need to do? ... If we're nagging them every term, there's no reason why they shouldn't progress.

With students who achieved well, he said: 'we could actually look potentially at students that are really flying and say, well, why don't you do early entry, let's put you in for a GCSE in the year nine'.

At the end of the year, James had developed his intervention further. Each student's test results were now plotted on a graph that showed progress towards the school's minimum target and to an aspirational target that was now set by the teacher, rather than the student. This was supported by a target-setting sheet in which students and teachers could record 'training needs'. James identified the advantages of the intervention, saying: 'It is highly visual ... progress is easily identified ... It is a clear way of communicating progress with students, teachers and parents'.

James reported that he had administered three termly tests and had entered the results on the pupils' graphs. He planned to continue using the graphs with those students who had started them, and to introduce the graphs to all next year's students aged 11-12. Reminded that he had previously been concerned about the motivational effects on lower-ability students, he said that he would now set target grades for all and, because the weakest students in his school could, according to Fischer Family Trust data, have a chance of attaining a C grade at GCSE, all students should have a chance of success. Different graphs, designed for different ability levels, would enable slower progress by less able students, to appear as impressive as faster progress by more able students.

James had shown the graphs to parents during a Parents' Evening; they were impressed by the clarity of the graphs compared with National Curriculum levels. The head teacher had reiterated his support for the project, describing it as 'fantastic' and asking James to develop it for the whole school. He had asked him to lead a SIG next year, focusing on students' progress and attainment and exploring 'how Heads of Department pick up underperforming students'. James had agreed because 'I'm interested in attainment and progress; in other words, have they [the students] met their target ... have they made progress?' He described his contribution as helping the heads of department to understand data: 
How they deal with that, afterwards, is not my concern. My part ... is to help them understand how to read data. Data doesn't tell you what the answer is, it tells you what the problem is.

Asked 'Did anything in your previous career influence your thinking on this project?' he answered:

Yeah, I've always worked with data. I ran a business before so I used to look at financial data ... it just happens that I'm dealing with pupil data rather than financial data; it's no different, really.

Discussion

Two views of education influence this study. Put crudely, the first sees the purpose of compulsory education as equipping students with the skills needed to keep the economy functioning effectively. Schools are required to demonstrate high performance through ever-improving examination results that are used to monitor the system, schools and individual students. Ball (2003) describes this view in terms of performativity; to Kemmis (2006) it leads to 'schooling'. The second view sees education as a means to realise each student's potential for self-actualisation. In it, education encourages dispositions such as curiosity, concern for others and the environment, perseverance and enjoyment of learning: dispositions that help individuals to pursue happy and fulfilled lives. To Kemmis (2006) this is 'education'; Amy described it as 'enriching and creative and happy'. Here, the curriculum is flexible, to meet the interests and needs of individuals, and assessment helps to ally teaching to these interests and needs.

As Ball (2003) describes, a shift has occurred from the latter view to the former and one of the major measures for assessing school performance, five good GCSE passes (Grades $A^{*}-C$ ), tends to dominate the priorities of many English secondary schools. This pushes schools towards an approach to education that sees 'consumers' acquiring the necessary qualifications to move into the workplace, schools being ranked according to their students' examination results and the consequences for low-achieving schools including public disgrace. 'Trinity' appears to ally itself with this view. It is concerned with examination results: students take examinations earlier than necessary, to enable them to have two attempts; there are booster classes, aimed at those students who are capable of getting ' $C$ ' grades, and teachers are deployed so as to maximise examination achievement. James appeared comfortable with the school's orientation, articulating his aim as 'to get them a GCSE, the best grade they could possibly get'. Asked 'if you had a choice between somebody getting a relatively low grade but enjoying the mathematics and somebody getting a high grade but actually turning off their mathematics for life, which would you go for?', he responded:

At the end of the day we are here to produce good grades. Someone [i.e. a student] said to me the other night ... that they wanted to go to be a vet and you need a grade $B$ to be a vet ... so what's my job? My job is to get them a grade B so that they can do what they want to do ... so we're a means to an end really. (James)

In his project, students were expected to be motivated by extrinsic means - seeing their rising progress, charted graphically. James felt 'comfortable' with his project, saying 'I don't see a lot of risk in doing this', and he received affirmation for his intervention, particularly from parents and the head teacher. These seemed to reinforce his sense of self-efficacy, fitting the school's priorities and values. Despite being involved in an action research project, James did not problematise how he taught or what he was trying to achieve. Indeed, his project, concerned primarily with the display of 
students' progress, suggests an understanding and acceptance of the prevailing culture, and generating what Ball, Maguire, and Braun call '... the visualisation of constant progression and the further constitution of the good school' (2012, 130-131). Therefore he did not experience what McNiff (2002) refers to as an 'internal tension' that needed resolution.

In contrast, Amy was more concerned with the pupils' experience of learning English. Initially she followed the school's priority of getting better results, but she had little idea of how this could be achieved other than sharing the higher-grade marking criteria with students. Further discussion revealed she was unhappy about being pigeon-holed as a teacher who got weaker pupils a good GCSE grade; instead she wanted pupils to share her passion for her subject and to enjoy learning English. To her these seemed mutually exclusive aims. Amy experienced a tension between what she was doing in the classroom and the sort of teacher she wanted to be. Amy came across as a risktaker, moving towards a position where she was concerned with putting her values into practice (McNiff 2002) and, to an extent, fighting against the 'system'. At times, most notably during the second interview, she looked for reassurance about the direction of her project; it seemed that she lacked a strong sense of her agency to bring about change. However, she gained confidence in her own views and position, supported by the nature of the project, her own reading, sense of dissatisfaction with the current situation and the support from some other staff. To an extent, the school structure curbed her actions: her GCSE class was changed, so she was forced back towards a position she had been resisting. Differences between the teachers' approaches to, and experience of, the project, are summarised in Table 1. A core difference between Amy and James appears in their conception of action research; whilst James saw it as a way of designing and testing an intervention, Amy saw it as an opportunity to learn. These conceptions can be seen in the way they interacted with us, their tutors, because, whilst Amy sought both support and challenge, James sought only external critique:

... an impartial observer, just to look at it and say, 'ok, what about this; what about that?' ... I'm in the thick of it so I would take decisions that I would take anyway, but it's someone coming in and saying 'why did you do that?' It's that sort of critical side of it, I suppose.

The findings from this project are interesting in terms of how individual teachers negotiate an action research project within the same institutional context. All participants were volunteers, suggesting a high level of motivation, yet they fell into different models of action research. James adopted an approach that could be termed 'technical' action research: he identified a problem, identified a practical solution and implemented it; his reflection being focused on the efficiency, effectiveness and visual clarity of the graphs used to display progress in mathematical tests. Amy showed signs of a more 'emancipatory' style of action research, where she was questioning the expectations the school had of her, and where she wanted to move beyond those confines to adopt a style of teaching and learning that would allow her to put her values more firmly into practice. Amy's experience suggests that emancipatory research for teachers requires: embracing a problem or issue to which the teacher does not already know the answer; being willing to take risks, and

Table 1. Apparent differences between the teachers during the project. 
Table 1. Apparent differences between the teachers during the project.

\begin{tabular}{|c|c|c|}
\hline & Amy & James \\
\hline \multirow[t]{5}{*}{$\begin{array}{l}\text { Conception of } \\
\text { action } \\
\text { research }\end{array}$} & $\begin{array}{l}\text { An opportunity to learn and } \\
\text { develop, personally and } \\
\text { professionally }\end{array}$ & $\begin{array}{l}\text { A chance to implement a pre-determined } \\
\text { intervention }\end{array}$ \\
\hline & Read other research & $\begin{array}{l}\text { Finished reading other research before } \\
\text { starting the project }\end{array}$ \\
\hline & Took risks & Risk-averse \\
\hline & $\begin{array}{l}\text { Required challenge and support } \\
\text { from a tutor }\end{array}$ & $\begin{array}{l}\text { Expected a tutor to provide an 'outside' } \\
\text { critical perspective }\end{array}$ \\
\hline & $\begin{array}{l}\text { Involved other teachers in the } \\
\text { research process }\end{array}$ & $\begin{array}{l}\text { Presented his intervention, as a finished } \\
\text { product, to other teachers }\end{array}$ \\
\hline \multirow[t]{3}{*}{ Aims } & $\begin{array}{l}\text { To gain personal satisfaction } \\
\text { from teaching }\end{array}$ & To monitor pupils' progress \\
\hline & To be a different type of teacher & To implement the findings of his MSc \\
\hline & $\begin{array}{l}\text { To help pupils better understand } \\
\text { expectations }\end{array}$ & $\begin{array}{l}\text { To improve pupils' understanding of } \\
\text { where they need to develop }\end{array}$ \\
\hline $\begin{array}{l}\text { Conception of } \\
\text { schooling }\end{array}$ & $\begin{array}{l}\text { For pupils to achieve and also to } \\
\text { enjoy learning (intrinsic } \\
\text { motivation) }\end{array}$ & $\begin{array}{l}\text { For pupils to achieve the best possible } \\
\text { grades, in order to get jobs (extrinsic } \\
\text { motivation) }\end{array}$ \\
\hline $\begin{array}{l}\text { Response } \\
\text { from } \\
\text { school }\end{array}$ & $\begin{array}{l}\text { School placed barriers by } \\
\text { changing her teaching timetable }\end{array}$ & $\begin{array}{l}\text { Head teacher described his work as } \\
\text { 'fantastic' }\end{array}$ \\
\hline
\end{tabular}

accept support for risks taken; understanding action research as potentially generating deep learning (from colleagues and supportive outsiders, as well as from reflection); and being willing to interrogate the self, including values and motivations.

The extent to which Amy's or James's position is the more typical is an interesting question; our view is that what Amy did and achieved was more unusual. This project suggests that, although not impossible, generating conditions for more emancipatory approaches to educational action research is difficult to achieve, in the present climate of performativity.

Conclusions

Although the distinction between technical, practical and emancipatory action research has been recognised since the 1980s (Grundy 1982; Carr and Kemmis 1986), the new culture of performativity has, we think, changed the landscape, at least in one school. In the 1980s it was possible to argue that educational practices would be improved if teachers collaboratively examined their practice in the light of the moral and ethical beliefs that underpinned them. Working together, teachers could transform irrational and undemocratic processes, emancipating themselves from irrationality, injustice, alienation and unfulfilment.

When action research turned out to be technical, it was probably because external agencies coopted teachers for their own purposes. In the new landscape it seems that this view cannot necessarily be sustained. The ways in which education is organised are no longer unintentionally and somewhat randomly irrational; rather, they are intentional and hyper-rational. As Ball (2003) 
pointed out, the language of teachers' beliefs (with the variety and individuality that this conveys) has been superseded - replaced by the language of corporate vision statements. The language of 'fulfilment', and the state this implies, has been replaced by the language of targets and customer satisfaction. Whether or not processes are democratic is no longer relevant, when the overriding issues are about 'performance' in the 'market'.

This project has taught us the importance of challenging teachers, as well as supporting them. We should probably have challenged James (and one or two of his colleagues) more strongly, because when teachers do not identify tensions between values and practice, their learning is likely to be controlled and superficial. We could also have withdrawn from the project, once it became clear that the research would not be more collectively embedded in collaborative school development, and perhaps we should have invested more time.

If the experiences of James and Amy are in any way typical, it seems that teachers' action research itself might need to change, in order to adapt to the new landscape. 'Outsider' assistance might need to balance support with challenge and involve school managers, who do not create the policy epidemic but interpret and implement policy. In a performativity culture, this will undoubtedly be difficult, particularly when many teachers do action research in order to achieve a master's degree (itself a symptom of performativity). But Amy's experience suggests that change is not impossible, although it might be uncomfortable. Paradoxically, it might even be easier because, whereas former decades have been characterised by many and varied challenges, the present decade has one overwhelming challenge: to reclaim the soul of the educational enterprise.

\section{References}

Anderson, G. L., K. G. Herr, and A. S. Nihlen. 1994. Studying Your Own School: An Educator's Guide to Qualitative Practitioner Research. Thousand Oaks, CA: Sage.

Ball, S. J. 2003. "The Teacher's Soul and the Terrors of Performativity." Journal of Education Policy 18 (2): 215-228.

Ball, S. J., M. Maguire, and A. Braun. 2012. How Schools Do Policy: Policy Enactments in Secondary Schools. London: Routledge.

Barker, B. 2008. "School Reform Policy in England since 1988: Relentless Pursuit of the Unattainable." Journal of Education Policy 23 (6): 669-683.

Carr, Wilfred, and Stephen Kemmis. 1986. Becoming Critical: Education, Knowledge and Action Research. London: Falmer Press.

Elliott, J. 1991. Action Research for Educational Change. Milton Keynes: Open University Press. Furlong, J., and J. Salisbury. 2005. "Best Practice Research Scholarships: An Evaluation." Research Papers in Education 20 (1): 45-83. 
Gewirtz, S., J. Shapiro, M. Maguire, P. Mahony, and A. Cribb. 2009. "Doing Teacher Research: A Qualitative Analysis of Purposes, Processes and Experiences." Educational Action Research 17 (4): 567-583.

Grundy, S. 1982. "Three Modes of Action Research." Curriculum Perspectives 3 (2): 22-34.

Haggarty, L., and K. Postlethwaite. 2003. "Action Research: A Strategy for Teacher Change and School Development?" Oxford Review of Education 29 (4): 423-448.

Hutchinson, B., and P. Whitehouse. 1986. "Action Research, Professional Competence and School Organisation." British Educational Research Journal 12 (1): 85-94.

Judah, M.-L., and G. H. Richardson. 2006. "Between a Rock and a (Very) Hard Place: The Ambiguous Promise of Action Research in the Context of State Mandated Professional Development." Action Research 4 (1): 65-80.

Kemmis, S. 2006. "Participatory Action Research and the Public Sphere." Educational Action Research 14 (4): 459-476.

Kemmis, S. 2007. "Action Research." In Educational Research and Evidence-Based Practice, edited by M. Hammersley, 167-180. London: Sage.

McNiff, Jean. 2002. Action Research: Principles and Practice. 2nd ed. London: RoutledgeFalmer.

Ponte, P., J. Ax, D. Beijaard, and T. Wubbels. 2004. "Teachers' Development of Professional Knowledge through Action Research and the Facilitation of This by Teacher Educators." Teaching and Teacher Education 20 (6): 571-588.

Priestley, M. 2002. "Global Discourses and National Reconstruction: The Impact of Globalization on Curriculum Policy." The Curriculum Journal 13 (1): 87-104.

Zeichner, K. M. 2003. "Teacher Research as Professional Development for P-12 Educators in the USA." Educational Action Research 11 (2): 301-325. 